\title{
A Psicologia Escolar e o estudante de Psicologia: elementos para o debate
}

\author{
Emilia Suitberta de Oliveira Trigueiro \\ Instituto Federal de Educação Ciência e Tecnologia do Ceará - CE
}

\section{Resumo}

A Psicologia Escolar foi uma das primeiras áreas de atuação do psicólogo, no entanto, desde o início, suas funções não estão bem definidas. A presente pesquisa teve por objetivo analisar a percepção dos estudantes de Psicologia de uma IES privada do interior do Ceará sobre a Psicologia Escolar. O estudo descritivo contou com a participação de 199 alunos entre o $1^{\circ} \mathrm{e}$ o $10^{\circ}$ semestre. A pergunta que norteou o trabalho foi: O que eles pensam sobre a Psicologia Escolar? Alguns citaram que a Psicologia Escolar atua nas relações escolares ou no desenvolvimento dos processos de ensino e aprendizagem e outros relacionaram-na ao trabalho com alunos e família, aos problemas de aprendizagem ou a problemas psicológicos. Percebe-se com isso que muitos dos participantes deste estudo citam o aluno e seus problemas como sendo o principal alvo de intervenções dentro da escola, reflexo de um discurso social culpabilizante e estigmatizador.

Palavras-chave: Formação do psicólogo; percepção; psicologia escolar.

\section{The school psychology and the psychology student: elements for debate}

\begin{abstract}
The school psychology was one of the first areas of the psychologist, however, from the beginning, their functions are not well defined. This study aimed to analyze the perception of psychology students from a private university in the state of Ceara on school psychology. The descriptive study had the participation of 199 students between the 1st and the 10th semester. The question that guided the work was: What do they think about school psychology? Some mentioned that the school psychology works in the school relations or development of teaching and learning processes and others related to school psychology to work with students and family, learning disabilities or psychological problems. It can be seen with so many of the students surveyed mentioned the student and his problems as being the main target of intervention within the school, reflecting a guilt-inducing social discourse and stigmatizing.
\end{abstract}

Keywords: Psychologist Education; perception; school psychology.

\section{La Psicología Escolar y el estudiante de Psicología: elementos para el debate}

\section{Resumen}

La Psicología Escolar fue una de las primeras áreas de actuación del psicólogo, sin embargo, desde el inicio, sus funciones no están bien definidas. La presente investigación tuvo por objetivo analizar la percepción de los estudiantes de Psicología de una IES privada del interior de Ceará sobre la Psicología Escolar. El estudio descriptivo contó con la participación de 199 alumnos entre el $1^{\text {er }}$ y el $10^{\circ}$ semestre. La pregunta que apoyó el trabajo fue: ¿Qué ellos piensan sobre la Psicología Escolar? Algunos dijeron que la Psicología Escolar actúa en las relaciones escolares o en el desarrollo de los procesos de enseñanza y aprendizaje y otros la relacionaron a la labor con alumnos y familia, a los problemas de aprendizaje o a problemas psicológicos. Se percibe con eso que muchos de los participantes de este estudio citan el alumno y sus problemas como siendo el principal blanco de intervenciones dentro de la escuela, reflejo de un discurso social de culpabilidad y estigmatizador.

Palabras-clave: Formación del psicólogo; percepción; psicología escolar. 


\section{Introdução}

Atualmente existe no Brasil um grande número de psicólogos atuando em diversas áreas, o que proporciona maior benefício para a população. No entanto, ainda existem muitas falhas na formação e atuação desses profissionais devido à bagagem histórica que carregam. Por isso se faz necessário observar e analisar as percepções e práticas dos profissionais de psicologia atuais e futuros.

A Psicologia brasileira como profissão tem apenas 51 anos, mas sua história é tão antiga quanto a história do país, tendo sido escrita durante muito tempo por religiosos, médicos e educadores, como pode-se perceber a seguir. Segundo Bock (2009), no início da história brasileira, devido à colonização com características fortemente exploratórias, se tornou necessária à construção de um forte aparelho repressivo, dada a necessidade de dominar e controlar os indígenas. Com o passar do tempo e o advento do Império, surge outra necessidade, a de higienização material e moral da sociedade, seguindo os ideais da medicina e da educação. Nesta época a educação era marcada pela busca do controle de impulsos considerados inadequados nas crianças, caracterizando-se por práticas disciplinares e moralistas.

Com a República surgiram outros ideais e necessidades. Um movimento representativo desse período foi a Escola Nova que, buscando valorizar a infância, aboliu os castigos e a vigilância disciplinar, trazendo à tona a vigilância psicológica. Com a chegada da industrialização tornou-se necessária a formação de grupos mais homogêneos nas escolas e a seleção de trabalhadores adequados nas empresas. Além disso, com as guerras que ocorreram nesse período, houve a necessidade de desenvolvimento dos testes psicológicos como prática diferenciadora e categorizadora (Bock, 2009). Segundo Patto (2009), os conhecimentos psicólogos produzidos durante essa época tinham como objetivo principal a formação de cidadãos exemplares, baseados num conceito de normalidade por meio do qual "normal é quem trabalha e obedece" (p. 32). A autora ainda afirma que durante muito tempo a Psicologia se constituiu como ciência que seleciona quem merece e quem não merece um lugar no sistema regular de ensino, quem será destinado a mandar e quem será destinado a obedecer, quem desempenhará o trabalho intelectual e quem desempenhará o trabalho braçal.

Nesse contexto a Psicologia se assegurou como profissão e, desde o início de sua existência até o momento atual, consagrou a Psicologia Clínica, a Escolar e a Organizacional como as três grandes áreas de atuação, com predomínio da primeira. Acredita-se que isso se deve ao fato de que desde os primeiros currículos de formação havia uma forte influencia da clínica, enfatizando a realização de psicodiagnóstico e práticas de psicoterapia e priorizando o atendimento individual do cliente.

Esse grande alcance da clínica atingiu outras áreas de atuação da Psicologia, entre elas a escolar. Os psicólogos escolares baseavam seu trabalho no modelo clínico de atendimento, fazendo uso de práticas psicométricas, psicoterapêuticas e reeducativas (Souza, 2007).

Esse modelo de atuação em Psicologia Escolar, baseado em práticas culpabilizadoras do aluno pelo seu insucesso, foi hegemônico durante muito tempo. Algumas mudanças começaram a se processar na década de 80 quando surgiram novas possibilidades de atuação sem culpabilização e novas compreensões da queixa escolar como sendo produto das relações escolares (Souza, 2009). No entanto, essas mudanças podem não ter atingido ainda a prática de todos os psicólogos e estudantes de Psicologia.

É nesse contexto que a presente pesquisa se insere, objetivando investigar a percepção de um grupo de estudantes de Psicologia a respeito da Psicologia Escolar, em termos de escolha da área para atuação e da visão destes sobre essa prática profissional. Acredita-se que o estudante de Psicologia, ao ingressar no curso traz consigo representações da atuação psicológica que são formadas pelas suas experiências com ela, mas também pelos ideais presentes em nossa sociedade e amplamente divulgados pela mídia. Durante o curso essas representações poderão sofrer modificações ou cristalizações. Assim, é de fundamental importância conhecer e analisar a percepção desses estudantes sobre a referida área, pois somente assim será possível oferecer contribuições para as discussões a respeito do avanço da Psicologia, em especial da Psicologia Escolar.

\section{Método}

A presente pesquisa desenvolveu-se por meio de um estudo de caso com os alunos do curso de Psicologia de uma IES privada, do interior do Ceará. O interesse pela investigação surgiu ao longo da disciplina Psicologia Escolar, ministrada no referido curso no $6^{\circ}$ semestre, sendo a única disciplina desta área na grade curricular. É relevante pontuar também que nessa instituição não há uma ênfase específica nesta área nos estágios curriculares. Considerando que a Psicologia Escolar é uma área importante de atuação e não é enfatizada durante o curso de Psicologia na instituição em questão, a pesquisa buscou investigar a percepção dos estudantes de Psicologia sobre a Psicologia Escolar, em termos de escolha da área para atuação e da visão destes sobre a prática deste profissional antes e depois do contato com este campo por meio da disciplina.

À época do estudo a instituição contava com cerca de 1.200 alunos, sendo a amostra composta por 199 estudantes que participaram voluntariamente do estudo, correspondendo a $16 \%$ do total. O procedimento de coleta de dados foi feito através de abordagem direta, realizada pelos alunos da disciplina de Psicologia Escolar. Como o objetivo da pesquisa seria comparar a percepção dos alunos sobre a Psicologia Escolar antes e depois de ter contato com ela por meio da disciplina, metade dos alunos pesquisadores abordou os alunos do início do curso, que ainda não haviam cursado a disciplina, e a outra metade os alunos do final do curso, que já haviam cursado a disciplina. Aos estudantes 
pesquisados foi explicada, de forma sucinta, a natureza e a importância da pesquisa e foi solicitada a colaboração destes. Assim, foram pesquisados 117 alunos do início do curso e 82 do final do curso.

O instrumento de coleta de dados foi composto por duas partes. Na primeira foi perguntado: "Em qual área da Psicologia você gostaria de atuar?". Foram listadas as seguintes opções: clínica, jurídica, políticas públicas (CRAS, CREAS, NASF, CAPS, etc.), hospitalar, escolar, organizacional, docência, pesquisa, outros, ainda não sei. Foi possibilitado ao aluno escolher mais de uma opção. Em seguida perguntou-se: "O que você acha da Psicologia Escolar?". É importante ressaltar que esta pergunta foi formulada de forma abrangente intencionalmente, para que tanto os alunos que já haviam tido contato com a disciplina, quanto aqueles não haviam tido contato pudessem se expressar.

Para a análise dos resultados, foi utilizada a abordagem qualitativa. Na primeira questão foi feito o somatório das respostas e a transformação em termos percentuais. $\mathrm{Na}$ segunda questão as respostas dadas pelos alunos foram listadas e categorizadas, e utilizou-se a teoria de Bardin (2011) para realizar a análise descritiva e explicativa.

\section{Resultados}

Participaram da pesquisa 199 alunos, sendo que 117 deles estavam no início do curso, entre o $1^{\circ}$ e o $5^{\circ}$ semestres, não tendo cursado ainda a disciplina de Psicologia Escolar.

Quando perguntou-se a esses alunos em que área da Psicologia eles desejariam atuar, 29,5\% apontou a clínica, $15,3 \%$ a área jurídica, $15,3 \%$ políticas públicas, $14,2 \%$ hospitalar, $8,2 \%$ escolar, $6,5 \%$ organizacional, $2,5 \%$ docência, $0,5 \%$ pesquisa e $7,6 \%$ ainda não sabem em que área desejam atuar. Esses dados podem ser visualizados no gráfico a seguir:

Gráfico 1. Áreas da Psicologia em que os alunos do início do curso desejariam atuar.

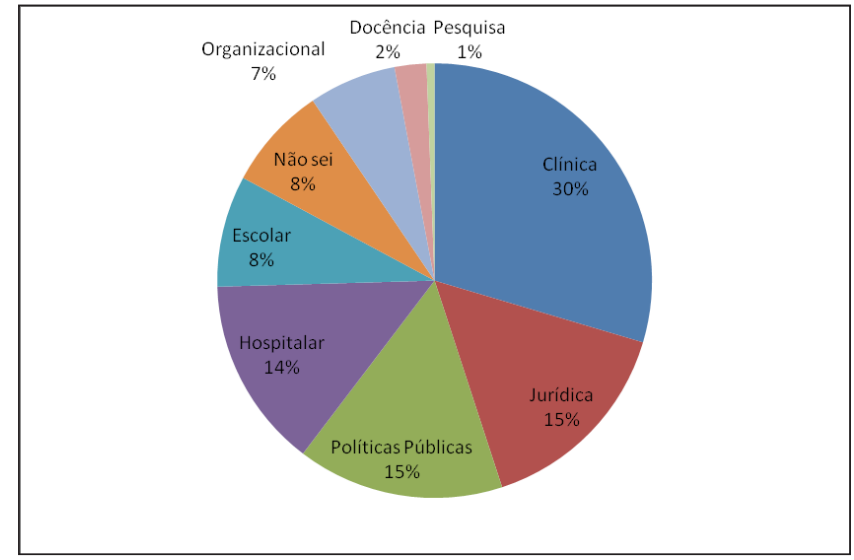

Fonte: O autor (2013)
Em seguida esses alunos foram indagados sobre o que achavam da Psicologia Escolar e as respostas foram distribuídas em categorias de acordo com a aproximação dos sentidos. $24,7 \%$ dos graduandos indicaram que a Psicologia Escolar trabalha com alunos e família, sendo respostas como as seguintes enquadradas nesta categoria:

\begin{abstract}
"Uma disciplina com um conteúdo grandioso, pois vem nos acrescentar no sentido de compreender no dia a dia o comportamento dos adolescentes e crianças assim podendo interagir com os pais na educação de cada um".

"É uma área da Psicologia que orienta e aplica teste que proporciona a melhor escolha do aluno em relação ao futuro e acompanha o rendimento do aluno".
\end{abstract}

Para $18,8 \%$ dos alunos a Psicologia Escolar é uma área de atuação da Psicologia, não tendo eles detalhado que tipo de ações esse profissional desenvolveria. Seguem exemplos de respostas:

"Sou a favor de profissionais que desejem atuar nessa área, pois vejo as escolas como um setor muito carente desse serviço".

"De enorme importância, principalmente nas escolas de área periférica."

$14,5 \%$ das respostas indicaram que o trabalho da Psicologia Escolar se dá no desenvolvimento do ensino e da aprendizagem.

"Muito importante a presença do psicólogo na escola, auxiliando, referenciando em suas teorias e técnicas o processo de aprendizagem e ensino e os demais assuntos".

De acordo com a resposta de $8,5 \%$ dos alunos a Psicologia Escolar trabalha com dificuldades de aprendizagem.

"Uma área que vai trabalhar no desenvolvimento da criança com algum déficit de aprendizagem".

Segundo 2,5\% dos alunos a Psicologia Escolar atua frente aos problemas psicológicos, como se percebe na seguinte resposta:

"Acredito ser muito importante para auxiliar na aprendizagem, educação dos estudantes. Ajuda a resolver problemas psicológicos que podem prejudicar no processo de aprendizagem das pessoas".

Somente $5,7 \%$ dos alunos indicam que esse profissional atua nas relações escolares.

"Importante, pois atua tanto com os diretores das escolas, professores, alunos. Com isso há uma melhora na aprendizagem dos alunos". 
$8,5 \%$ dos alunos citam que é uma área importante, mas que não possuem identificação pessoal para atuar nela. $5,7 \%$ das respostas foram vagas, imprecisas ou inconsistentes e 10,2\% dos alunos responderam que não saberiam responder ou deixaram a questão em branco.

O outro grupo de respondentes foi composto pelos estudantes que já haviam cursado a disciplina de Psicologia Escolar, estando no final do curso, entre o $7^{\circ}$ e o $10^{\circ}$ semestres, totalizando 82 alunos.

Em relação à área da Psicologia em que eles desejavam atuar surgiram as seguintes respostas: $23,2 \%$ políticas públicas, $18,6 \%$ clínica, $13,9 \%$ organizacional, 12,4\% hospitalar, 10\% docência, 8,5\% jurídica, 6,9\% escolar, 2,3\% pesquisa, 3,8\% ainda não sabe. Esses dados podem ser observados no seguinte gráfico:

Gráfico 2. Áreas da Psicologia em que os alunos do final do curso desejariam atuar.

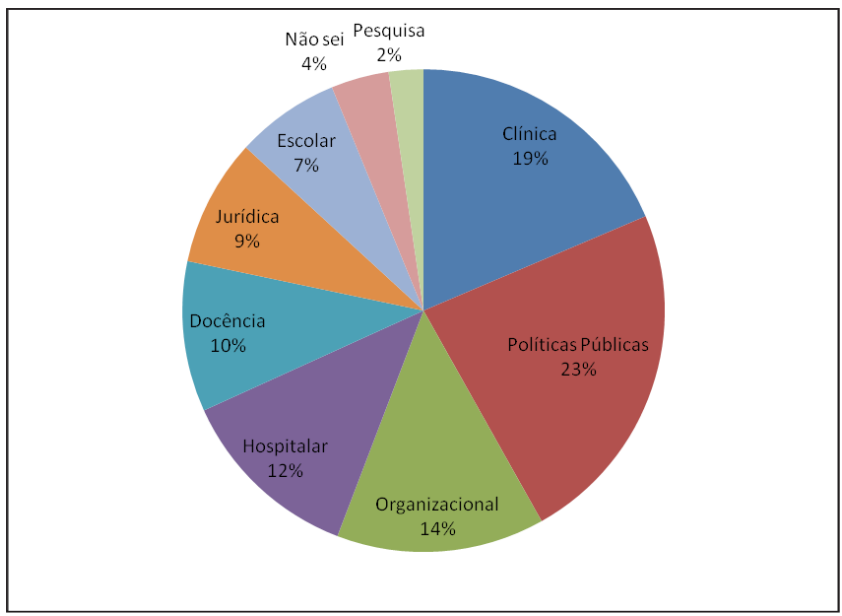

Fonte: O autor (2013)

Sobre o que esses alunos acham da Psicologia Escolar, 35,3\% das respostas indicaram apenas que é uma área de atuação da Psicologia, não sendo detalhadas as ações dessa área.

"Muito importante, porém não atuante, fala-se muito e não faz quase nada".

"É uma área que necessita de mais investimentos, ainda é muito pequeno, mas deve ser reconhecida e incentivada".

$23,1 \%$ das respostas indicaram que a Psicologia Escolar atua nas relações escolares.

"A Psicologia Escolar é uma área muito importante, pois atua no trabalho com alunos, professores, pais".

"Acredito ser de grande relevância para toda escola. Os alunos, professores, coordenação e pais podem ser beneficiados quando esse serviço é oferecido com todas as suas particularidades".
Para 10,9\% dos alunos o psicólogo escolar trabalha com alunos e família, como pode ser percebido pelas seguintes respostas:

"A Psicologia Escolar é uma área bastante interessante, pois vê além das dificuldades cognitivas, vendo o estudante como um todo e como os processos familiares e sociais que perpassam a vida da criança influenciam o seu desempenho na escola".

"Acho de extrema importância, pois muitos alunos precisam de acompanhamento, pois existem problemas na família que podem prejudicar os estudos dos mesmos e a psicologia escolar pode ajudar esses alunos".

De acordo com a resposta de $4,8 \%$ dos alunos, a Psicologia Escolar trabalha com as dificuldades de aprendizagem.

"Uma área específica escolar com a finalidade de trabalhar os problemas que interferem na eficácia escolar (rendimento) do aluno seja ele na posição de aluno estrela, como aluno problema".

"O psicólogo escolar vem para acolher o aluno, a família e até mesmo a escola. Ele vem equilibrar a relação entre ambos com estratégias para solucionar problemas que interferem na evolução da vida educacional da criança. É uma área muito importante da psicologia".

Em 4,8\% das respostas pode-se inferir que a Psicologia Escolar atua frente aos problemas psicológicos.

"Uma área interessante e necessária para todas as instituições de ensino. Por meio desta podem ser detectados vários problemas que envolvem professores, alunos, funcionários, família, e a partir disto um possível acompanhamento psicoterápico".

"Uma forma de interagir o psicólogo às escolas [sic], com intuito de buscar uma melhor interação dos comportamentos dos estudantes, suas causas e sintomas, sobre qualquer problema ou transtorno que venha a ocorrer para com elas e o psicólogo ajudará a amenizar esses fatos".

Outra atuação do psicólogo escolar citada na pesquisa foi a de desenvolvimento do ensino e aprendizagem, contabilizando $3,6 \%$ das respostas.

“De suma importância para a educação no Brasil. Tem papel importante para auxiliar no ensino e nas dinâmicas metodológicas. Ajuda ao professor, ao aluno e a instituição fazerem seu papel correto de ensino e aprendizagem com qualidade".

$3,6 \%$ das respostas foram enquadradas na categoria denominada atuação crítica, pois estas relacionam o traba- 
Iho da Psicologia Escolar com todos os fatores e atores que estão nela envolvidos. Seguem exemplos dessas respostas:

"É uma excelente área de atuação, pois é sabido que cada vez mais os psicodiagnósticos vêm do meio escolar para a clínica e outras instituições, a ausência desse profissional psicólogo escolar acarreta esse estereótipo da psicologia, fazendo dos alunos com alguma problemática o "aluno problema", dentre outras questões que venham a surgir na equipe pedagógica".

"É um campo amplo com muitas coisas para serem trabalhadas e aperfeiçoadas. Pois o psicólogo na instituição escolar é muitas vezes visto como aquele que vai consertar o aluno, fazendo clínica na escola e a realidade não é essa em se tratando das diretrizes do CRP".

$7,3 \%$ das respostas citam a Psicologia Escolar como sendo importante, mas sem identificação pessoal para atuar nela; $4,8 \%$ foram consideradas vagas, imprecisas ou inconsistentes e 1,2\% dos alunos não soube responder ou deixou a questão em branco.

\section{Discussão}

Sabe-se que no Brasil a Psicologia clínica ao longo do tempo tem atraído a atenção de grande parte dos psicólogos, e vários estudos mostram essa tradição. Podem ser mencionados os estudos de Bastos e Gomide (1989) e o de Yamamoto (1990) que citam como principais áreas de atuação dos psicólogos a clínica, a organizacional, a escolar e a docência, nesta ordem de preferência. Pesquisa feita junto aos Associados do Conselho Federal de Psicologia (2001) encontrou resultados semelhantes, sendo também citadas outras áreas como Psicologia da Saúde, Psicologia do Trânsito, Psicologia Jurídica, Psicologia Social, Psicologia do Esporte e pesquisa.

Esses resultados são semelhantes aos encontrados na presente pesquisa nas respostas dos alunos do início do curso, dos quais $29,5 \%$ apontam a clínica como sendo sua principal área de interesse seguida da jurídica, políticas públicas, hospitalar, escolar, organizacional, docência e pesquisa, o que pode indicar que a representação que eles têm da Psicologia é fortemente centrada na Psicologia Clínica, com menor interesse em outras áreas, entre elas a escolar.

Por outro lado, pesquisas mais recentes como a de Bardagi, Bizarro, Andrade, Audibert e Lassance (2008) mostram que estão ocorrendo mudanças nesse padrão. Em seu estudo eles apontam que a área clínica ainda é a que concentra o maior número de profissionais recém formados, com $26,4 \%$, no entanto outras atuações são citadas, como o envolvimento em atividades de mestrado, doutorado, pesquisa, consultoria, ministrar curso/ palestras e atividades práticas de extensão/ residência/ especialização, sendo que a área da Psicologia Escolar não foi citada no estudo.
A pesquisa realizada por Martins, Matos e Maciel (2009) também encontrou resultados diferentes dos tradicionais, com a Psicologia organizacional sendo a mais citada, seguida da Psicologia clínica, Psicologia social/ saúde/ comunitária, Psicologia Escolar e docência em Psicologia. Percebe-se nesses resultados o crescimento de áreas como a organizacional e a social em comparação com outras pesquisas, o que mostra que a clínica pode estar perdendo sua hegemonia.

Esses resultados são semelhantes aos encontrados neste levantamento com os alunos que estão na segunda metade do curso de Psicologia, que expressam os seguintes interesses: $23,2 \%$ políticas públicas, $18,6 \%$ clínica, $13,9 \%$ organizacional, $12,4 \%$ hospitalar, $10 \%$ docência, $8,5 \%$ jurídica, $6,9 \%$ escolar, 2,3\% pesquisa. Esses percentuais podem indicar uma mudança ocorrida no decorrer do curso devido às experiências com outras áreas de atuação. No entanto, mesmo depois de cursar a disciplina de Psicologia Escolar, que é o objeto de interesse desta pesquisa, os alunos não demonstram uma preferência maior por esta, passando de $8,2 \%$ no início para $6,9 \%$ no final.

Acredita-se que esses resultados se devem ao fato de que mesmo com tantas possibilidades de atuação na área da Psicologia, o ideal de muitos psicólogos ainda é atuar na clínica. Magalhães, Straliotto, Keller e Gomes (2001) corroboram esse pensamento ao questionar estudantes de Psicologia do primeiro ano de faculdade sobre a escolha da Psicologia como profissão, e identificar que o modelo de atendimento individual em consultório foi o ideal de atuação psicológica projetado por muitos sujeitos, sendo o desejo destes ser admirados pelos seus pacientes devido a seus poderes de cura. Para os indivíduos do estudo supracitado, áreas como a escolar e a sócio-comunitária não são objetos de interesse, pois seria impossível ao psicólogo realmente ajudar essas pessoas, já que não poderia acompanhá-las de perto.

Nesse sentido, observa-se que esse modelo clínico de atendimento individual tem repercussões para a sociedade, pois como Patto (2009) aborda, ele cria uma naturalização da desigualdade, que se origina na maneira como a sociedade se estrutura, mas é interpretada como diferença biológica ou psicológica de aptidão intelectual. Há uma responsabilização das pessoas pelos seus próprios processos de desenvolvimento, pelo sucesso e pelo fracasso obtido.

Em relação ao contexto escolar, tal modelo individualizante vê as dificuldades de aprendizagem como sendo de responsabilidade somente do sujeito, e a intervenção clínica do psicólogo teria como objetivo contribuir para que o próprio sujeito possa se desenvolver e se curar, quando for o caso. Essa concepção isola o indivíduo e sua subjetividade do mundo social e isenta as instituições, entre elas a escola, de qualquer responsabilidade pelos sofrimentos psicológicos (Bock, 2009). Esse modelo foi o predominante na atuação do psicólogo escolar durante muito tempo, e tinha como principal foco do trabalho o aluno problema.

Souza (2007), analisando prontuários psicológicos de atendimento à queixa escolar em clínicas-escola de cur- 
sos de Psicologia na cidade de São Paulo, identificou que as hipóteses explicativas da queixa escolar eram centradas em aspectos individuais ou familiares, de natureza física ou emocional. Segundo a autora, isso ocorreria porque a Psicologia estaria utilizando um saber que enfatiza o mundo interno do sujeito, determinado pelas relações vividas no grupo familiar primário, como sendo o grande responsável por todos os seus problemas psicológicos e de aprendizagem. Essa explicação não levaria em conta que grande parte das dificuldades se produz na escola, pela inadequação como essa criança é tratada, que os problemas emocionais não recaem sobre a maciça maioria das crianças, e que o espaço pedagógico também é um importante elemento estruturante do psiquismo e promotor de relações mais saudáveis. Essas explicações individualizantes da queixa escolar, no entanto, ainda estão presentes no discurso de muitos psicólogos, estudantes de Psicologia e da sociedade em geral.

$\mathrm{Na}$ presente pesquisa percebeu-se que quando questionados sobre a atuação do psicólogo escolar, a maioria dos alunos que ainda não teve contato com a disciplina relatou que o foco do trabalho recai sobre os alunos e suas famílias, como pode-se observar na seguinte resposta:

\footnotetext{
"Uma disciplina com um conteúdo grandioso, pois vem nos acrescentar no sentido de compreender no dia a dia o comportamento dos adolescentes e crianças, assim podendo interagir com os pais na educação de cada um".
}

Esses alunos também relatam que a atuação do psicólogo está voltada para o desenvolvimento do ensino e aprendizagem, para o trabalho com dificuldades de aprendizagem e para problemas psicológicos. Eles acreditam que o trabalho do psicólogo é importante "para ajudar a resolver problemas psicológicos que podem prejudicar no processo de aprendizagem das pessoas." Pequena parte dos alunos, 5,7\%, cita a atuação nas relações escolares como foco de trabalho do psicólogo escolar. Por outro lado, 10,2\% dos alunos dizem que não têm opinião sobre a Psicologia Escolar ou deixaram a questão em branco e 8,5\% relatam que é uma área importante, mas que não possuem um interesse pessoal por ela.

Em relação aos alunos que já tiveram contato com a disciplina de Psicologia Escolar a maioria das respostas indica que a área atua nas relações escolares $23,1 \%$, o que se considera um fator positivo, e pode ser observado na seguinte resposta:

\footnotetext{
"Acredito ser de grande relevância para toda escola. Os alunos, professores, coordenação e pais podem ser beneficiados quando esse serviço é oferecido com todas as suas particularidades".
}

Considera-se positivo também o fato de 3,6\% das respostas indicarem uma atuação numa perspectiva crítica. No entanto, ainda é citado como possibilidade de atuação o trabalho com alunos e suas famílias, suas dificuldades de aprendizagem e seus problemas psicológicos. As seguintes respostas ilustram essas categorias:
"Acho de extrema importância, pois muitos alunos precisam de acompanhamento, pois existem problemas na família que podem prejudicar os estudos dos mesmos e a psicologia escolar pode ajudar esses alunos".

"Uma área interessante e necessária para todas as instituições de ensino. Por meio desta podem ser detectados vários problemas que envolvem professores, alunos, funcionários, família, e a partir disto um possivel acompanhamento psicoterápico".

Como se percebe, tanto nas respostas dos alunos do início do curso quanto do final do curso há divergências, com indicações de várias possibilidades de atuação. Pode-se levantar a hipótese de que grande parte desses alunos pode não ter tido contato com a Psicologia Escolar em sua vida acadêmica pregressa, visto que esta ainda é restrita a algumas instituições, o que pode gerar dúvidas a respeito do que este profissional realmente faz na escola.

Sabe-se que as dificuldades que são produzidas na escola são multideterminadas e a queixa escolar não é fruto somente do aluno e de suas dificuldades psicológicas e familiares. No entanto, o foco de atuação de muitos psicólogos escolares ainda é o aluno. É o que mostra a pesquisa desenvolvida pelo Conselho Federal de Psicologia (2009), respondida por 302 psicólogos que atuam na educação básica. Essa investigação mostrou que as principais práticas desses profissionais, $57,8 \%$, estão voltadas para orientação/ educação, avaliação psicológica, acolhimento/ assistência/ tratamento psicológico. No estudo de Yamamoto (1990), os psicólogos escolares também citaram que o principal foco de atuação no seu trabalho é o aluno e as atividades realizadas são psicodiagnóstico, observações, aplicação de testes, orientação vocacional, orientação psicopedagógica, atendimento de distúrbios de aprendizagem e atendimento psicoterápico.

Como pode ser percebido, a representação dos alunos pesquisados sobre o trabalho do psicólogo escolar voltado para o aluno e seus problemas psicológicos e de aprendizagem encontra eco nas práticas de muitos profissionais. Por outro lado, muitas são as dificuldades encontradas por este profissional no desempenho do seu trabalho. No estudo de Yamamoto (1990) foram citadas as seguintes: pouca abrangência do trabalho, falta de recursos materiais, falta de apoio administrativo, falta de aceitação do trabalho, descaso com a educação, e por fim o reconhecimento da indefinição de sua função.

Esse mesmo problema de indefinição do papel do psicólogo escolar também atinge os alunos em formação. Balbino (2008) realizou pesquisa com 18 estagiários em Psicologia Escolar, que relataram como dificuldades encontradas no estágio o despreparo para atuar em Psicologia Escolar e também a falta de compromisso dos professores, além de falta de recursos, desinformação dos pais e alunos sobre a Psicologia Escolar e falta de apoio da diretoria. $\mathrm{Na}$ mesma pesquisa buscou-se investigar também a percepção das escolas sobre a Psicologia Escolar através de seus di- 
retores ou coordenadores. Quando se questionou sobre a importância do trabalho do psicólogo escolar, 95\% dos entrevistados nas escolas relataram ser importante e no que se refere às dificuldades encontradas pela escola em relação ao estágio foram citadas: falta de um psicólogo escolar para atuar em conjunto, desconhecimento por parte da clientela e do professorado sobre o psicólogo e seu trabalho, pouco envolvimento dos participantes nas atividades, pouco tempo para realização das atividades e dificuldade de trabalhar com o professorado.

Essas dificuldades relatadas pelos profissionais, pelos estagiários e pelos diretores ou coordenadores das escolas também são percebidas nas respostas de 10,2\% dos alunos do início do curso e de $1,2 \%$ dos alunos do final do curso que não souberam falar nada sobre a Psicologia Escolar, e dos $8,5 \%$ do início do curso e $7,3 \%$ do final do curso que dizem não ter identificação para atuar na área. Guzzo (2008) acredita que muitos psicólogos não sabem como agir nas escolas porque não aprenderam ou não vivenciaram essa realidade em seu tempo de formação, ou porque diante de uma realidade difícil e complexa, os conhecimentos psicológicos e ferramentas profissionais têm pouco a contribuir. Ela acredita também que muitas práticas psicológicas desenvolvidas nas escolas são fruto da expectativa que a população cria a respeito do profissional de Psicologia de que ele atue no modelo médico, culpabilizando o indivíduo pelo seu problema e tratando-o, de preferência, longe do seu contexto de desenvolvimento.

Essa expectativa seria construída ideologicamente e seria fruto do contexto social em que nos encontramos. Esse contexto é refletido, e ao mesmo tempo é reflexo do discurso oficial que propõe os modelos de sociedade que devem ser seguidos. Para a Psicologia Escolar também são propostos modelos a serem seguidos, através, por exemplo, das proposições legislativas que versam sobre sua inserção na educação básica. Pasqualini, Souza e Lima (2013), analisando essas proposições buscaram investigar quais demandas sociais reivindicam a presença do psicólogo na educação, e concluíram que nessas proposições o que se espera do profissional de Psicologia é que atue predominantemente focando no indivíduo, já que a concepção que embasaria esta atuação é a de que esses profissionais seriam formados para atuar auxiliando, individualmente, participantes do ambiente escolar cujos problemas de ordem individual, biológica e/ou familiar estejam dificultando o processo de aprendizagem.

Por outro lado, nesta pesquisa, 26 alunos relataram que o trabalho do psicólogo escolar também se dá nas relações escolares e que este pode e deve ter uma atuação crítica nas escolas. Quando o aluno diz que a Psicologia Escolar é "uma excelente área de atuação, pois é sabido que cada vez mais os psicodiagnósticos vêm do meio escolar para a clínica e outras instituições, a ausência desse profissional psicólogo escolar acarreta esse estereótipo da psicologia, fazendo dos alunos com alguma problemática o "aluno problema", ele está fazendo uma crítica a este modelo de atuação vigente, que está por trás da resposta de vários outros alunos. Por outro lado, outro aluno, ao dizer que a Psicologia Escolar é importante principalmente na "área periférica", expressa uma série de preconceitos contra a escola de área periférica e o aluno que a frequenta. Esses preconceitos e estereótipos precisam ser trabalhados dentro do espaço acadêmico para que não atinjam a prática desses futuros profissionais.

Sabe-se que o trabalho do psicólogo é importante e vasto dentro do contexto educacional, pois ele pode atuar desde a Educação Infantil até a universidade. O trabalho nessa área tem crescido muito, mas ainda há a necessidade de que cada vez mais profissionais atuem nessa especialidade. Por isso Joly (2000) acredita que é imprescindível e urgente a capacitação ética, flexível e competente desses profissionais nos cursos de graduação. Isso irá formar indivíduos críticos e competentes para serem agentes de mudanças e geração de novos conteúdos para a sociedade.

\section{Considerações finais}

Nesta pesquisa buscou-se investigar a percepção dos estudantes de Psicologia de uma IES privada do interior do Ceará a respeito da Psicologia Escolar em termos de escolha da área para atuação e da visão sobre a prática desse profissional, e analisar se esta percepção sofreria mudança após o contato com esta por meio da disciplina de Psicologia Escolar. Com a análise das respostas dos alunos percebeu-se que áreas como a clínica, as políticas públicas, a organizacional e a jurídica são as que mais despertam o interesse dos mesmos, sendo a Psicologia Escolar pouco citada.

Em relação à percepção sobre a Psicologia Escolar, os alunos que ainda não tiveram contato com ela através da disciplina associaram sua atuação principalmente ao trabaIho com os alunos e suas famílias, ao desenvolvimento do ensino e aprendizagem e às dificuldades de aprendizagem. Os alunos que já tiveram contato com ela a associaram à atuação nas relações escolares, ao trabalho com alunos e famílias e às dificuldades de aprendizagem.

Percebe-se nas respostas dos alunos uma mudança, ainda que pequena, ao ter contato com a disciplina em relação ao principal foco do trabalho do psicólogo escolar, que passa do aluno e sua queixa para as relações que ocorrem no interior da escola. Isso pode trazer o rompimento com a culpabilização dessas crianças e a construção de novas compreensões da queixa escolar. Por outro lado, alguns alunos continuam com um pensamento clínico enraizado, expressando em suas respostas a perspectiva psicométrica e psicoterápica da Psicologia. Acredita-se que isso esteja relacionado ao estereótipo social da Psicologia como sendo uma área que atua individualmente com os pacientes, que possuem em si a causa e a solução para seus problemas. Esse estereótipo teria sido construído ao longo do tempo na história do nosso país, e estaria presente em muitos de nós, sendo apenas refletido nas respostas desses alunos.

Parte dos alunos, tanto do início quanto do final do curso, relatou não ter identificação para trabalhar nesta área $(7,9 \%)$, apesar de considerá-la importante, e 5,7\% não 
souberam falar nada a respeito. Considera-se isso um dado preocupante, pois o estudante de Psicologia ao concluir sua graduação forma-se um profissional generalista, que poderá atuar em qualquer área da Psicologia, mas para isso deve ter um mínimo de conhecimento e experiência em todas as áreas. Um dado relevante sobre o estudo é o fato de que na instituição pesquisada há apenas uma disciplina obrigatória nesta área e não há uma ênfase específica nos estágios curriculares do curso, o que limita as experiências do aluno em relação a essa temática. É importante ressaltar que vários projetos de lei em tramitação visam garantir a presença do psicólogo em toda rede de educação básica, o que irá criar um grande espaço para inserção desse profissional, e quando isso acontecer tanto os profissionais interessados na área quanto os não interessados poderão atuar nesses espaços.

Por fim, considera-se que conhecer a percepção dos estudantes de Psicologia sobre esta temática irá possibilitar discussões aprofundadas a respeito, o que pode contribuir com o avanço da Psicologia Escolar. Considera-se também que o estudo teve suas limitações como o fato de analisar poucos aspectos da percepção dos alunos sobre o tema, e ter sido investigada somente uma instituição de ensino. Coloca-se como recomendação o aprofundamento do estudo com análise de outras variáveis, a replicação em outras instituições e, principalmente, a análise e a reformulação da grade curricular do curso na referida instituição com ampliação das possibilidades de discussão deste tema.

\section{Referências}

Balbino, V. C. R. (2008). Estágios em psicologia escolar: reflexões e relato de uma pesquisa na Universidade Federal do Ceará. Em V. C. R. Balbino (Org.), Psicologia e psicologia escolar no Brasil: formação acadêmica, práxis e compromisso com as demandas sociais (pp. 52-68). São Paulo: Summus.

Bardagi, M. P., Bizarro, L., Andrade, A. M. J., Audibert, A., \& Lassance, M. C. P. (2008). Avaliação da Formação e Trajetória Profissional na Perspectiva de Egressos de um Curso de Psicologia. Psicologia: Ciência e Profissão, 28 (2), 304-315.

Bardin, L. (2011). Análise de conteúdo. São Paulo: Edições 70.

Bastos, A. V. B., \& Gomide, P. I. C. (1989) O psicólogo brasileiro: sua atuação e formação profissional. Psicologia: Ciência e Profissão, $9(1), 6-15$.

Bock, A. M. B., (2009). Psicologia e sua ideologia: 40 anos de compromisso com as elites. Em A. M. B. Bock (Org.), Psicologia e o compromisso social (pp 15-28). São Paulo: Cortez.
Conselho Federal de Psicologia (2001). Pesquisa feita junto aos Associados do Conselho Federal de Psicologia - Relatório Final. Brasília: Autor.

Conselho Federal de Psicologia (2009). Atuação dos psicólogos em Políticas Públicas da Educação Básica - Relatório da Pesquisa. Brasilia: Autor.

Guzzo, R. (2008). Psicologia em instituições escolares e educacionais. Em Conselho Federal de Psicologia (Org.), Ano da psicologia na educação- textos geradores. Brasília: Autor.

Joly, M. C. R. A. (2000). A formação do psicólogo escolar e a educação no terceiro milênio. Psicologia Escolar e Educacional, 4 (2), 51-55.

Magalhães, M., Straliotto, M., Keller, M., \& Gomes, W. B. (2001). Eu quero ajudar as pessoas: a escolha vocacional da psicologia. Psicologia: Ciência e Profissão, 21 (2), 10-27.

Martins, K. P. H., Matos, T. G. R., \& Maciel, R. H. M. O. (2009). Formação em psicologia e as novas demandas sociais: relato dos egressos da Universidade de Fortaleza. Revista Mal-Estar e Subjetividade, 9 (3), 1023-1043.

Pasqualini, M. G., Souza, M. P. R., \& Lima, C. P. (2013). Atuação do psicólogo escolar na perspectiva de proposições legislativas. Psicologia Escolar e Educacional, 17 (1), 15-24.

Patto, M. H. S. (2009). O que a história tem a dizer sobre a profissão do psicólogo: a relação Psicologia - Educação. Em A. M. B. Bock (Org.), Psicologia e o compromisso social (pp. 29-35) São Paulo: Cortez.

Souza, M. P. R. (2007). Prontuários revelando os bastidores; do atendimento psicológico à queixa escolar. Em B. P. Souza (Org.), Orientação à queixa escolar (pp. 27-58). São Paulo: Casa do Psicólogo.

Souza, M. P. R. (2009). Psicologia Escolar e Educacional em busca de novas perspectivas. Psicologia Escolar e Educacional 13(1), 179-182.

Yamamoto, O. H. (1990). A psicologia escolar em Natal: características e perspectivas. Psicologia: Ciência e Profissão, 10 (2-3-4), 40-49.

Recebido em: 18/09/2013

Reformulado em: 30/04/2014

Aprovado em: 11/06/2014 


\section{Sobre a autora}

Emilia Suitberta de Oliveira Trigueiro (emiliatrigueiro@hotmail.com)

Mestre em Políticas Públicas e Gestão da Educação Superior pela Universidade Federal do Ceará. Graduada em Psicologia pela Universidade Federal da Paraíba (2008). Psicóloga Escolar do Instituto Federal do Ceará campus do Crato.

Agradecimentos: Aos alunos de Psicologia das turmas 104.6 e 306.6 da Faculdade Leão Sampaio pela colaboração na coleta dos dados. 
